\title{
'AINDA VÃO ME MATAR NUMA RUA': DIREITO À CIDADE, VIOLÊNCIA CONTRA LGBTS E HETEROCISNORMATIVIDADE NA CIDADE- ARMÁRIO
}

\author{
'THEY ARE STILL GOING TO KILL ME IN A STREET': \\ RIGHT TO THE CITY, VIOLENCE AGAINST LGBT AND \\ HETEROCISNORMATIVITY IN THE CLOSET-CITY
}

\author{
Claudio Oliveira de Carvalho \\ Gilson Santiago Macedo Júnior
}

\section{RESUMO}

Este trabalho objetiva melhor compreensão, partindo da perspectiva crítica do Direito à Cidade, dos fenômenos crescentes de invisibilidade e violência contra lésbicas, gays, bissexuais, travestis e transexuais nos espaços urbanos, sob a construção ideológica do que chamamos 'cidade-armário'. Partindo desta análise, entende-se o cruzamento entre fatores como sexualidade e identidade de gênero na construção e reprodução dos espaços urbanos. Sendo assim, ao catalogar as causas do fenômeno, através de uma pesquisa qualitativa e quantitativa, esse estudo chama a atenção que, a cidade-armário consiste na utilização dos espaços públicos para a mitigação e apagamento das sexualidades e/ou identidades de gênero desviantes, que fomenta discursos de ódio contra LGBTs.

Palavras-chave: Cidade-armário. Direito à Cidade. Heterocisnormatividade.

\section{ABSTRACT}

This paper intends to clarify the rising phenomena of invisibility and violence against lesbians, gays, bisexuals, transvestites and transsexuals individuals in the urban spaces, under the ideological construction of what we call "closetcity" from the standpoint of the Right to the City. This analysis allows the understanding of the intersection between factors such as sexuality and gender 
identity in the reproduction of the urban spaces. Therefore, when cataloging as causes of the phenomenon, through a qualitative and quantitative research, this study draws attention what, the closet-city consists of the utilization of the public spaces for the mitigation and erasure of the sexualities and/or the deviant gender identities, which encourages the hate speeches against LGBTs.

Keywords: Closet-city. Right to the City. Heterocisnormativity.

\title{
INTRODUÇÕES: QUAIS AS VIAS DE ENTRADA NA CIDADE?
}

\author{
Ainda vão me matar numa rua. \\ Quando descobrirem, \\ principalmente, \\ que faço parte dessa gente \\ que pensa que a rua \\ é a parte principal da cidade \\ (LEMINSKI, 2013, p. 24)
}

A cidade é uma obra sempre por finalizar. Em constante transformação e aquisição de novos sentidos, a urbe mescla culturas, identidades visuais e sonoras num caldeirão efusivo e demasiado complexo para se categorizar: a cidade adquire vida com as produções e intercâmbios culturais de seus citadinos. A (re)produção do espaço urbano não pode ser dissociada da construção ideológica, visto que o espaço em que os cidadãos passam suas vidas é constantemente remodelado e adequado à produção de subjetividades dos próprios citadinos.

Tornar as cidades habitáveis hoje não basta por si só; é urgente pensar numa cidade para além das torres altas que servem à especulação imobiliária: é urgente tornar as cidades mais humanas, partindo da compreensão da cidade como um palco constante de disputas entre os citadinos, sobretudo disputa ideológica para a (re)modelagem dos espaços urbanos. É preciso compreender um processo cada vez mais afunilado de "espacialização da cidadania" (SANTOS, 2014) nas cidades. Essas relações são pautadas entre o trabalhar e o viver, o que torna a noção de luta de classes aplicada aos conflitos urbanos pedra angular para a compreensão da construção ideológica de cidades democráticas. 
Sobre a concepção não hegemônica da democracia, Santos e Avritzer (2002, p. 51) afirmam que essas apresentam a "ênfase na criação de uma nova gramática social e cultural e o entendimento da inovação social articulada com a inovação social, isto é, com a procura de uma nova institucionalidade da democracia". Santos (2002, p. 458) contribui ao falar que:

O Brasil é uma sociedade com longa tradição de política autoritária. A predominância de um modelo de dominação oligárquico, patrimonialista, burocrático resultou em uma formação de Estado, um sistema político e uma cultura caracterizados pelos seguintes aspectos: a marginalização, política e social, das classes populares, ou a sua integração através do populismo e do clientelismo; a "artificialidade" do jogo democrático e da ideologia liberal, originando uma discrepância entre o "país legal" e o "país real".

Assim, Carvalho e Rodrigues (2016, p. 71) afirmam que "quanto mais a população citadina se conscientizar das causas das mazelas urbanas, quanto mais se apropriar das diversas instâncias de participação, mais a cidade será um reflexo de suas perspectivas". Souza (2003, p. 53) complementa, ainda, que:

A democratização cada vez maior da ação coordenadora do Estado, abrindo-se para incorporar elementos de democracia participativa tanto na gestão como no planejamento, é uma alternativa à submissão acrítica ao mercado - submissão essa que é fonte de crescente esgarçamento do tecido social - e aos "facismos societais" discutidos por Boaventura de Sousa Santos (1999).

0 direito à cidade se insere na ótica de direitos coletivos, bem como a luta das mulheres, trabalhadores e LGBTs (lésbicas, gays, bissexuais, travestis e transexuais), contestando uma lógica de mercado que se constitui de forma hegemônica e liberal. Portanto, o direito à cidade, constitui-se um desafio de se propor crítico à mercantilização da cidade, isto é, a produção capitalista do urbano, de tal modo que se torna indissociável - sob risco de deixar de ser crítico - a concepção de cidade que temos e queremos, das noções de ideologia dominante.

A construção dos espaços urbanos eivados de contradições, conflitos e produzidos num viés de aprofundamento da desigualdade socioespacial 
é reflexo de um modelo de produção e acumulação de capital, que torna a cidade um palco para disputas. Assim, é a partir desses embates ideológicos, estendidos do particular para o público, que temos a configuração de um fenômeno antigo, porém pouco analisado: a cidade-armário - uma construção ideológica que orienta a produção e reprodução do espaço urbano a partir da heteronormatividade e da violência contra lésbicas, gays, bissexuais, travestis e transexuais na cidade.

Percebe-se que a classe dominante deseja "transformar a mentalidade dos oprimidos, e não a situação que os oprime” (BEAUVOIR, p. 34). No mesmo sentido, Millett aponta que o sexo é uma "categoria de status com implicações políticas". Ela desafia o status quo, ao afirmar: "Mesmo com a aparência muda em que ela pode se apresentar, a dominação sexual obtém sobretudo, a talvez mais perversa ideologia de nossa cultura, e fornece seu mais fundamental conceito de poder. (MILLETT, 1970).

Diante do exposto, o presente trabalho tem por objetivo discutir, utilizando-se de uma metodologia pautada numa pesquisa bibliográfica e qualitativa, que a cidade-armário não é somente um termo para designar o apagamento das sexualidades e identidades de gênero desviantes ao moralmente aceitável, mas uma denúncia à invisibilidade que legitima a violência. Dentro da perspectiva crítica da crise urbana, esse aspecto torna-se melhor compreendido pela lente dialética da luta de classes, será ela, através dos seus jogos de manutenção do status quo, que nos guiará na compreensão melhor desse fenômeno, o que demonstraremos ao longo deste trabalho. Adicionalmente, ao fenômeno da invisibilidade e, consequentemente, da violência contra lésbicas, gays, bissexuais, travestis e transexuais, serão analisadas, a cidade-armário e a expansão do "armário" - entendido aqui como o ambiente de proteção/ocultação da sexualidade desviante à norma - para o âmbito urbano. 


\section{“AINDA VÃO ME MATAR NUMA RUA": VIDA E MORTE NA CIDADE-ARMÁRIO}

Jamais se deve confundir uma cidade com o discurso que a descreve (CALVINO, 1990, p. 59)

A cidade poderia ser entendida como uma grande escrita (ROLNIK, 2012), onde os diversos poderes atuantes inscrevem novas realidades. A realidade socioespacial é constantemente transformada pelas relações de produção e acumulação de capital - Lefebvre (1991) entendia a cidade como um lugar de investimento das riquezas até então não gastas, transformando a cidade numa obra de arte complexa -, de modo que há um processo de reificação da classe trabalhadora: a cidade, enquanto objeto, passa a valer mais do que quem a produz.

Dialogicamente, ao transformar a natureza, o homem se transforma e se molda para pertencer à nova realidade engendrada, transformando, por conseguinte, as relações sociais que possui. Dentro da ótica capitalista, as relações humanas podem ser analisadas a partir do aspecto majoritário de suas vidas: o trabalho. A partir das relações de trabalho e as transformações decorrente delas, é que os indivíduos criam/ assimilam ideias e valores que permearão suas relações sociais. A cidade não se mantém impassível perante as transformações de pensamento. A cidade é pensada, consoante a Lefebvre (1991), constituindo-se num sistema fechado, assimilando não só o caráter da vida comunitária, mas os conflitos internos e os interesses dominantes na sua constituição. Precisamos pensar que "o território em que vivemos é mais que um simples conjunto de objetos, mediante os quais trabalhamos, circulamos, moramos, mas também um dado simbólico" (SANTOS, 2014, p. 82).

Rolnik (2009) nos afirma que as legislações urbanísticas, ao demarcarem territórios, são responsáveis por demarcarem vidas e, por conseguinte, demarcarem relações de poder existentes em um determinado espaço, ou, assim podemos dizer, economias de poder. Tratase de criar linhas invisíveis que delimitam uma cartografia escancarada da realidade urbana, demarcando espaços do cidadão e espaços marginais, uma vez que "o poder político frequentemente procura reorganizar as 
infraestruturas urbanas e a vida urbana com o objetivo de manter as populações insatisfeitas sob controle. [...] 0 urbano funciona como um espaço importante de ação e revolta política" (HARVEY, 2014, p. 212-3).

Portanto, a constituição do urbano, vimos, é uma constituição do pensamento. As relações entre os sujeitos se constituem, nas suas medidas, relações permeadas por valores dominantes à época, que se fazem vivos e capazes de alterar as subjetividades. Tais valores dominantes à época são ideologias que refletem a ideologia da classe dominante. Afinal, a cidade é um palco político, eivado de pessoas que, por sua vez, possuem ideologias diversas. No mesmo sentido, Lefebvre (1991, p. 22) nos aponta que "a vida urbana pressupõe encontros, confrontos das diferenças, conhecimentos e reconhecimentos recíprocos (inclusive no confronto ideológico e político) dos modos de viver".

Portanto, a cidade é construída não somente de aço e concreto, mas de gente, de vida pulsante que disputa espaço nela e, consequentemente, "cuanto mas crece la ciudad, dice Lefebvre, cuanto mas se desarrolla y expande, extendiendo sus tentaculos hacia todas partes, mas se degradan las relaciones sociales, mas se disloca la sociabilidad en sus articulaciones"1 (MERRYFIELD, 2011, p. 102).

Ora, se a cidade - por meio da acumulação e exploração do capital - é moldada a partir dos interesses das classes dominantes, é óbvio chegar à conclusão de que a cidade tem donos. Os donos da cidade são aqueles que detêm meios de produção, poderio social e político, e são capazes de ajustar as cidades às normas estabelecidas por esses setores. Para Marx e Engels (2009, p. 67), "as ideias da classe dominante são, em todas as épocas, as ideias dominantes, ou seja, a classe que é o poder material dominante da sociedade é, ao mesmo tempo, o seu poder estrutural dominante". Isso significa dizer que a classe dominante estende a toda a sociedade as suas ideias, de forma universal, apresentando-as como as únicas válidas e se valendo do confronto social para sua manutenção. Notemos com atenção o cruzamento da sexualidade e da identidade de gênero com o urbano: os espaços urbanos não são 'assexuados', mas possuem vedações morais que, sutilmente, interditam a presença de pessoas que questionam a (re)produção da heterocisnormatividade ${ }^{2}$. 
A ausência de políticas públicas urbanas para lésbicas, gays, bissexuais, travestis e transexuais visando sua proteção e a garantia de acesso aos direitos capazes de afirmar o princípio basilar da dignidade da pessoa humana, é uma prova gritante que a cidade se fecha em torno da heterossexualidade e da cisgeneridade, ignorando a presença e participação de LGBTs em seu corpo. Uma vez que não existem políticas públicas voltadas para essa população, temos dois fenômenos que são interligados: a invisibilidade social LGBT - embora não esteja invisível nos relatos de violência urbana em virtude de discriminação - e a redefinição da cidade enquanto "cidade-armário".

Segundo o Relatório 2017: Mortes violentas de LGBT no Brasil, do Grupo Gay da Bahia (GGB) ${ }^{3}$, somente em 2017, 445 (quatrocentos e quarenta e cinco) LGBTs foram vitimados no país, equivalendo a uma morte a cada 20 (vinte) horas. Esse dado representa um aumento de 30\% em relação às mortes violentas de LGBTs no ano de 2016 (343 mortes registradas). Dessas 445 mortes, $43,6 \%$ das vítimas eram gays, 42,9\% pessoas transexuais/travestis, 9,7\% lésbicas, $1,1 \%$ bissexuais e $2,7 \%$ das vítimas eram heterossexuais confundidos com gays. A nível global, a organização Transgender Europe aponta o Brasil como líder em mortes de travestis e transexuais, representando $52 \%$ das mortes registradas deste segmento entre 71 países $^{4}$.

Quanto à causa mortis, 30,8\% dos assassinatos no Brasil, no ano de 2017, foram praticados com arma de fogo, 25,2\% com instrumentos perfuro-cortantes. Além disso, muitos crimes são cometidos com requintes de crueldade, como tortura, decapitação e queima do corpo. $37 \%$ das mortes ocorreram dentro da própria residência, $56 \%$ em vias públicas e $6 \%$ em estabelecimentos privados. Travestis e profissionais do sexo geralmente são assassinadas a tiro ou espancadas na rua. No Brasil, São Paulo é o Estado com maior número de assassinatos por motivação LGBTfóbica: 59 mortes documentadas, seguido por Minas Gerais (43) e Bahia (39).

A rua, assim, se torna um lugar de descontrole, de medo e insegurança para LGBTs, em que toda afetividade é julgada e toda expressão de desejo é moralmente condenada: a rua representa o caos, porque possui regras de convivência social diversas. Novos cálculos, novas ponderações, novas análises sobre as pessoas que ocupam estes espaços precisam ser refeitos, 
como numa economia política dos pensamentos e dos afetos. A figura do armário, deste modo, torna-se um fantasma constante, demarcando os territórios em que assumir-se ou manter-se no armário torna-se uma autêntica 'escolha de Sofia'. "Viver no armário, e então sair dele, nunca são questões puramente herméticas. As geografias pessoais e políticas são, antes, as mais imponderáveis e convulsivas do segredo aberto" (SEDGWICK, 2007, p. 21). A rua representa, socialmente, o medo e o descontrole. Mas a casa também. "É ingenuidade pensar que a efetivação da dignidade humana pode ser estruturada sem considerar o espaço onde as pessoas passam a quase totalidade de suas vidas. [...] A cidade deve ser um espaço de realização dos direitos humanos, sem qualquer discriminação" (CARVALHO; RODRIGUES, 2016, p. 46-54).

Se a rua, este espaço coletivo de trocas e cruzamentos, representa um risco grande de existência e, até mesmo, de demonstração de afetos e relacionamentos, é preciso se questionar acerca da produção desses espaços enquanto espaços de sociabilidade. Se a cidade deve ser um espaço livre de discriminação, por que lésbicas, gays, bissexuais, travestis e transexuais são tão vulneráveis nos espaços urbanos? A explicação mais lógica possível reside no fato de que "o espaço se reproduzirá em função das necessidades ditadas pela sociedade de modo geral, que, por sua vez, será determinada pelo poder de barganha das classes que a compõem. O processo de reprodução espacial, envolve [...] uma sociedade hierarquizada" (CARLOS, 2008, p. 134).

A hierarquia social é, na verdade, fruto de uma subjugação que ocorre na luta de classes. A produção espacial tem gênero, classe, raça e orientação sexual: é a dominação do masculino, burguês, branco e heterossexual pela constituição de locais "de família" ou espaços "de respeito". Conseguimos pensar a cidade como um ambiente de corpos transitando livremente ou enxergamos locais reservados a determinados corpos? Uma análise apurada poderia situar-nos que, perante a cidade, lésbicas, gays, bissexuais, travestis e transexuais não existem - ou não deveriam existir - porque rompem com as normas e acordos de sexualidade tácitos feitos pelos poderes atuantes no regime sobre os corpos. Uma vez que assumimos que a cidade não é produzida visando o coletivo, mas sim a partir das visões de uma determinada classe, 
precisamos reposicionar nosso olhar sobre a ela. Por isso, a cidade deve ser entendida como uma construção, sobretudo, ideológica. Lefebvre (1991), nesse sentido, nos chama atenção:

A consciência da cidade e da realidade urbana se esfuma tanto nuns como noutros, até desaparecer. A destruição prática e teórica (ideológica) da cidade não pode, aliás, ser feita sem deixar um vazio enorme. Sem contar os problemas administrativos e outros cada vez mais difíceis de serem resolvidos. (LEFEBVRE, 1991, p. 21)

As ideias da classe dominante, isto é, as ideias dominantes à época, se sustentam através de sistemas já arraigados na sociedade, impedindo a consciência de classe e fortalecendo a exploração e o aprofundamento das desigualdades sociais. Foucault (2003) acredita que a passagem para o capitalismo marcou um momento de confissão do sexo e das sexualidades, estimulando o falar de si, como confissão de segredos; para ele, o dispositivo sexual, isto é, o poder sobre o sexo se exerce de mesmo modo a todos os níveis. Assim, a sexualidade não diz respeito mais somente à esfera privada, passando para o campo público e se tornando cada vez mais uma manifestação política nos espaços urbanos; ao mesmo tempo, porém, em que instiga o falar de si, a urbe se fecha àqueles que são opostos aos padrões pré-estabelecidos de sexualidade e de gênero.

Em verdade, não existem vazios políticos na cidade: estes serão sempre preenchidos com as ideias dominantes, afinal, é visando a garantia das relações de poder que a cidade se estrutura e se remodela. Através da moral e da ideologia dominante, aliadas ao patriarcalismo e à heterocisnormatividade, é que a cidade se ergue como expressão da divisão capitalista, sendo marcada pela invisibilidade social de determinados grupos e pela reprodução de uma moral da classe dominante (SILVA, 2011). Foucault (1995, p. 8) ensina que há um regime de verdade, criado através dos discursos, uma vez que "a verdade está circularmente ligada a sistemas de poder, que a produzem e apoiam, e efeitos de poder que ela induz e que a reproduzem".

Cada sociedade tem seu regime de verdade, sua "política geral" de verdade: isto é, os tipos de discurso que ela acolhe e faz funcionar como verdadeiros; 
os mecanismos e instâncias que permitem distinguir os enunciados verdadeiros dos falsos, a maneira como se sanciona uns e outros; as técnicas e os procedimentos que são valorizados para a obtenção da verdade; o estatuto daqueles que têm o encargo de dizer o que funciona como verdadeiro (FOUCAULT, 1995, p. 12)

0 poder vinculado através dos discursos é que funda um espaço urbano baseado em binarismos: homem e mulher, heterossexual e homossexual, lícito e ilícito etc., não dando conta das múltiplas configurações humanas (BORGHI, 2015). Por não assimilar além dos binarismos e por ser uma reprodutora de mecanismos e dinâmicas sociais, a cidade também se constitui palco para as violências contra as minorias sociais, mitigando subjetividades e definindo condutas apropriadas ou não aos seus ambientes. Por meio do discurso - através dos binarismos -, a figura do armário é colocada como um ambiente necessário à preservação da privacidade das pessoas consideradas desviantes da norma sexual: o que não é norma deve ser ocultado, uma vez que representa risco à ordem sexual vigente. Porém, a figura do armário é, também, uma estrutura definidora da opressão (SEDGWICK, 1998).

Segdwick (1998, p. 96) nos afirma que "la imagen de la salida del armario suele interactuar con la imagen del armario, y su emplazamiento público aparentemente inequívoco se puede contraponer como una certeza epistemológica de salvación contra la ambigua privacidad que ofrece el armario ${ }^{5}$ ". A saída do armário "[...] não é uma escolha individual, e a decisão de sair dele tampouco depende da 'coragem' ou 'capacidade' individual. Em contextos heterossexistas, 'assumir-se' pode significar a expulsão de casa, a perda do emprego ou, em casos extremos, até a morte” (MISKOLCI, 2009, p. 172).

0 armário é silêncio. Mas também é fala.

O próprio mutismo, aquilo que se recusa dizer ou que se proíbe mencionar, a discrição exigida entre certos locutores não constitui propriamente o limite absoluto do discurso, ou seja, a outra face de que estaria além de uma fronteira rigorosa mas, sobretudo, os elementos que funcionam ao lado de (com e em relação a) coisas ditas nas estratégias de conjunto. Não se deve fazer divisão binária entre o que se diz e o que não se diz; é preciso tentar determinar as diferentes maneiras de não dizer, como são distribuídos os 
que podem e os que não podem falar, que tipo de discurso é autorizado ou que forma de discrição é exigida a uns e outros. Não existe um só, mas muitos silêncios e são parte integrante das estratégias que apoiam e atravessam os discursos (FOUCAULT, 2003, p.30).

Assim, precisamos entender quais as formas pelas quais se conduz ao silenciamento e à invisibilidade. Sabemos que o armário conduz ao mutismo, à proibição de se explicitar o sexo, afirmando, num primeiro momento, uma tese repressiva. Porém, como nos recorda Foucault (1995, p. 29), "somos submetidos à produção da verdade e só podemos exercer o poder mediante a produção da verdade”; assim, a hipótese repressiva não se sustenta, uma vez que o corpo é obrigado a produzir verdades sobre si, afinal, a passagem para o capitalismo marca momento de confissão em que o discurso deve explicitar o sexo, sob o risco de punição não por ter explicitado, mas pela ocultação de algo que deveria ser dito. A cidade armário passa a ser confessionário das sexualidades, mas apenas aquelas permitidas; os corpos adequados podem transitar livremente pela cidade e acessar seus mais diversos serviços, mas àqueles corpos não-dóceis, resta o medo da rua, o medo da cidade. 0 segredo, através do armário, pode constituir-se como

[...] la práctica subjetiva en la que se establecen las oposiciones de privado/ público, dentro/fuera, sujeto/objeto y se mantiene inviolada la santidad de su primer término. Y el fenómeno del 'secreto a voces', como se podría pensar, no provoca el desmoronamiento de estos binarismos y sus efectos ideológicos, sino que constata su fantasmagórico restablecimiento (MILLER, 1988, p. 207 apud SEDGWICK, 1998, p. 92) ${ }^{6}$

A negação dos espaços públicos à população LGBT reforça a ideia de um dualismo entre a cidade legal e a cidade ilegal, em que as figuras que transgridem as normas de gênero e de sexualidade devem ser execradas. A situação, aparentemente, insuperável do grande armário social produz economias sobre o sexo e a sexualidade através do discurso da normalidade/anormalidade, definindo, limitando, apagando e invisibilizando tudo aquilo que seja prejudicial à ordem sexual posta. É interessante à produção espacial capitalista essas marginalizações, posto que as ordens urbanas se fundamental em preceitos estéticos do 
capital; como numa máquina, as engrenagens do machismo, patriarcalismo, LGBTfobia e exploração social do proletariado se combinam e funcionam de forma harmônica, perpetuando pelos mecanismos dissimuladores desses sistemas a invisibilização e, consequentemente, a violência contra lésbicas, gays, bissexuais, travestis e transexuais.

Às travestis, - que não possuem a figura do armário para ocultar sua identidade, vez que "[...] sofrem maior violência e preconceito porque a marca da transgressão é nítida, visual e, portanto, afronta o poder heteronormativo, muito menos evidente no gay ou na lésbica" (SILVA, 2008, p. 11) - é reservada a cidade noturna, quando todos dormem e não podem mais ver seus corpos, não podem mais ver essa vida nua e insacrificável; às travestis não é dado o direito de se locomover pela cidade, de acessar os serviços de saúde, educação e aparato jurídicopolicial: tudo lhes é negado, exceto a marginalização social, porque situam-se fora das normas do Direito. A sua cidadania é incompleta, posto que não existem para a organização das cidades e “[...] não existir, do ponto de vista burocrático ou oficial para a administração da cidade, é estar fora do âmbito de suas responsabilidades com os cidadãos" (ROLNIK, 2009, p. 2). Ser marginal na cidade, isto é, estar à margem das políticas urbanas "implica ter de assumir a condição de não-cidadão, estigmatizado por desviar da norma. A estigmatização destes 'focos' de desvio faz parte do mecanismo poderoso de reprodução do modelo de cidade e cidadão" (ROLNIK, 2012, p. 74).

Para Carvalho e Rodrigues (2016) a segregação socioespacial entre privilegiados e desfavorecidos pela ordem urbana se justifica pelos fins estéticos e econômicos, uma vez que "o sistema precisa que eles [marginalizados] continuem na cidade - ou melhor, à margem da cidade - de modo que estes indivíduos só deverão ser removidos dali se algum interesse imobiliário passar a admirar aquelas redondezas" (CARVALHO; RODRIGUES, 2016, p. 30). Evitar que prostitutas, bichas, viados e sapatões e travestis circulem livremente pela cidade é uma forma de fortalecer e valorizar o senso estético da cidade. Para tanto, a moralização dos comportamentos sexuais é uma arma forte e sutil: torna-se imoral que a cidade, que a todo tempo torna pública seu sexo, seja obrigada a conviver com essas vidas indignas de viver. 
Si ciertas vidas se consideran merecedoras de vivir, de protección y de ser lloradas, y otras no, entonces esta manera de diferenciar las vidas no puede entenderse como un problema de identidad, ni siquiera de sujeto. La cuestión es más bien cómo el poder forma el campo en el que los sujetos se vuelven posibles o cómo se vuelven imposibles. Lo cual implica una práctica de pensamiento crítico que se niegue a dar por sentado ese marco de lucha identitaria que presupone que dichos sujetos ya existen, que ocupan un espacio público común y que sus diferencias podrían reconciliarse disponiendo, simplemente, de las herramientas adecuadas para unirlos (BUTLER, 2010, p. 224-5) ${ }^{7}$

\section{"DISCRETO E FORA DO MEIO": OS ARMÁRIOS CRIADOS PELOS APLICATIVOS DE ENCONTROS}

Bauman (2004), numa análise sobre o amor e a fragilidade dos laços humanos, aponta que modernidade traz como consequência uma espécie de desengajamento, em que os relacionamentos estão a um clique do início ou término. Adicionar, bloquear, mostrar-se ou ocultarse são estratégias de envolvimento por meio dos apps de encontro e, consequentemente, de sociabilidade.

A cidade do século XXI se tornou palco para o desenvolvimento de novas interações entre os sujeitos - majoritariamente homens gays - a partir de smartphones, de modo a proporcionar novas práticas e experiências, vez que "no que se refere às novas tecnologias em interface com o espaço público, a ideia de mobilidade é central para conhecer as novas características das cidades contemporâneas" (LEMOS, 2005, p. 4). Com o avanço da tecnologia, é possível saber onde determinada pessoa se encontra, quais os ambientes mais seguros e como chegar a determinado local. Hoje, todos os apps de relacionamento gay utilizam-se de sistemas de geolocalização para facilitar o encontro de pessoas próximas.

Ao percorrer tais vias de desejo e afetividade, poderíamos traçar uma cartografia dos desejos, mapeando os locais usados por sujeitos não-heterossexuais para encontros, de tal modo que notaríamos, com certa facilidade, o cruzamento do espaço com a vida sexual do sujeito - em muitas cidades, por exemplo, é corriqueiro encontrar banheiros 
públicos que servem como local para relações sexuais entre indivíduos de mesmo sexo, como são os chamados 'banheirões'. Há grupos fetichistas que se valem do espaço público para fins sexuais, sentindo prazer com a possibilidade de serem vistos e/ou pegos durante o sexo. Assim, a cidade comporta qualquer um durante a noite, mas se fecha durante o dia.

A facilidade para se encontrar uma pessoa (que, nos apps, pode ser classificada em características - as tags - permitindo uma identificação entre os sujeitos a partir das suas preferências sexuais) é uma característica marcante da cidade-armário tecnológica: conectar-se e desconectar-se, ver e ser visto, ocultar e bloquear são ferramentas nãodisponíveis na vida real que proporcionam aos sujeitos uma relação muito mais rápida e precisa em seus objetivos. É preciso que os encontros sejam breves, sem vínculos e sob absoluta discrição dos envolvidos, em sua maioria, como num acordo tácito. Assim, a web tornou-se um ambiente inédito e, aparentemente, mais confiável para relacionar-se com pessoas que fogem à norma sexual.

Enquanto a web amplia as possibilidades já existentes para relações heterossexuais, para pessoas que buscam se relacionar com outras do mesmo sexo a rede criou um espaço inédito para se socializar. Historicamente alijadas da maior parte do espaço público, sexualidades marginalizadas tenderam a se restringir a locais de encontros e espaços reduzidos das grandes cidades, deixando pouca ou nenhuma opção para a maioria que vivia (e vive) em cidades médias, pequenas, na zona rural ou mesmo na periferia das metrópoles (MISKOLCI, 2009, p. 175)

Miskolci (2009) argumenta, ainda, que os guetos gays migraram para a internet, de modo que se torna impossível estar 'fora do meio'. Tal expressão, bastante utilizada por usuários que buscam 'discrição' e 'sigilo total', revela um caráter estigmatizante e até mesmo - ainda que paradoxalmente - homofóbico, visando o apagamento da sua própria constituição enquanto gay. Ser discreto deixou de significar, no contexto dos apps, manter sigilo, passando a representar o desejo de se camuflar enquanto heterossexual; estar fora do meio representa a vontade de se dissociar da compreensão que se faz da homossexualidade como promíscua. Significa ainda reproduzir o comportamento dito 
masculino para evitar sua associação ao estigma homossexual: passivo, afeminado e promíscuo (MISSE, 2007). Assim, ser 'discreto e fora do meio' representa a dissociação de qualquer coisa que possa associar o sujeito ao homossexual, forjando uma identidade quase heterossexual ou menos heteronormativa.

Os aplicativos de relacionamento - tais como Grindr, Scruff, Hornet e Tinder, com exceção deste, voltados exclusivamente para o público gay transformam o espaço virtual em ambiente de práticas de 'sociabilidade homoerótica' (MISKOLCI, 2009). Tais práticas, muitas vezes, se iniciam no plano virtual e se consolidam no plano real, criando uma nova forma de vivenciar a realidade urbana a partir do interdito, porém, "a internet revela sua dupla face: facilitadora de contatos e constituição de redes, mas mantenedora da imagem dominante do espaço público como sinônimo de heterossexualidade" (MISKOLCI, 2009, p. 176).

Em uma breve análise pelos perfis dispostos nesses aplicativos, na tentativa de uma cartografia dos desejos, perceberíamos a quantidade esmagadora de sujeitos que optam por revelar - nas fotos de perfil - apenas uma parte do corpo, comumente o tórax, escondendo o rosto ou revelando-o parcialmente, além de usarem nomes fictícios, visando a preservação social de sua identidade real. Em seus perfis, seria possível identificar, facilmente, as palavras: 'sigilo', 'discreto', 'macho' e 'não afeminado'.

Existe uma forte busca pela representação do ideal masculino em todas as imagens descritas nos perfis, demonstrando a importância da aparência viril para os parceiros, bem como para descrever a si mesmo. A força, como o contraponto da fraqueza, é forma de inclusão desse homem que atende às exigências sociais para com a sua performance e representação de gênero (KELLER, ARAÚJO \& CORSO, 2015, p. 172).

Essas definições de gênero e sexualidade são baseadas em imperativos sociais e culturais, de modo que há uma determinação apriorística que define, limita e mitiga as subjetividades que escapam às normas sexuais. A definição é, portanto, presa à categoria de sexo, sua divisão em homens e em mulheres reporta à explicação biológica. Para Wittig (1992), ao ser feita essa conversão "naturaliza-se a história e se passa a crer que homens e mulheres sempre existiram e sempre 
existirão do mesmo modo" (WITTIG, 1992, p. 10). Para Bourdieu (2014), a definição de papeis baseados na dualidade masculino/feminino é perpassado pelo processo de construção simbólica, impondo a virilidade como um fator determinante para a construção da própria masculinidade. Deste modo, tudo que se assimila à feminilidade não é desejável pela masculinidade, uma vez que é preciso um corpo másculo e forte para ser homem nesta visão.

Os papeis de gênero/sexualidade acabam constituindo, nestes aplicativos que - pretensamente - seriam neutros ou democráticos estruturas definidoras de opressão relativa à figura do armário, vez que "ser discreto é, portanto, não exteriorizar a identidade homossexual, ou seja, ater-se à adequação estabelecida pela doxa cultural" (KELLER, ARAÚJO \& CORSO, 2015, p. 160). Deste modo, a compreensão da cidadearmário implica dizer que a cidade é o efeito, também, de um desejo ou de muitos desejos que resistem a aceitar que a urbe não seja também o outro mundo onde todos queremos viver.

\section{CONSIDERAÇÕES FINAIS: FINALMENTE ABRINDO AS PORTAS DO ARMÁRIO?}

Pensar a construção ideológica da cidade significa, muitas vezes, se aventurar em suas camadas mais profundas para encontrar resíduos em sua superfície. A cidade é erguida com concreto e pensamentos, ideias e blocos. Impossível seria pensar a cidade de modo asséptico, ou acrítico, sem levar em conta que o espaço em que as pessoas vivem é constantemente permeado pelos valores que vigem nestes espaços. Há códigos morais explícitos e implícitos que trazem grande distinção entre o que comumente se pensa como espaço público versus espaço privado.

Enxergar os armários sociais erguidos pela cidade, que impedem a efetivação da cidadania - intimamente ligada à cultura e ao território (SANTOS, 2014) - significa ver nas tessituras da cidade as raízes e as consequências da exclusão e da cidadania incompleta de pessoas LGBT. A democratização dos espaços urbanos perpassa a possibilidade das 
pessoas poderem vivenciar a cidade com a devida liberdade de expressão para serem quem são verdadeiramente.

A percepção ideológica de um projeto de cidade calcado nos princípios de uma sociedade fechada em si mesma, avessa à alteridade, é tarefa que só podemos fazer com as vistas mais apuradas pelas lentes das lutas de classes e compreendendo aspectos da geografia feminista e da geografia queer; constitui-se, por exemplo, desafio maior pensar identidades subalternas para além do convencionado pelo queer identidades condizentes com a experiência local (latino-americana e, preferencialmente, brasileira), sobretudo no que diz respeito às travestis, de modo que não seja este mais um pensamento colonizante/colonizado, mas uma práxis inovadora e uma nova epistemología del sur; o desafio de pensar corpos que se locomovem e vivenciam a cidade em suas múltiplas faces; a luta deve ser por uma vida vivível em sua plenitude, em seus mais diversos aspectos, sem obstáculos que atravessem sua efetividade.

Desta clareza que abordamos desde as primeiras linhas, é preciso tornar as cidades mais humanas, e para isto não basta que as cidades sejam repletas de espaços de comum convivência. As cidades só serão mais humanas em tempo que forem democráticas em seu acesso - a cidadania não pode estar condicionada às plataformas político-eleitorais ou à territorialidade -, sendo preciso pensar o espaço dos cidadãos nessa nova ordem urbanística. 0 direito à cidade não poderá se eximir de traçar a crítica à espacialização da cidadania, denunciada por Milton Santos na década de 1980, tampouco se esquivar do cruzamento da raça, sexualidade, gênero, identidade de gênero e classe social com o tecido urbano. A divisão moral da cidade em espaço de respeito, espaço de família, não é saudável para a democracia dos espaços públicos, tampouco para a segurança de pessoas que não se enquadrem nesse modelo prédeterminado de família ou do que é moral.

A invisibilização de lésbicas, gays, bissexuais, travestis e transexuais causa um apagamento desejado e promove a noção de que tais vidas não são passíveis de luto (BUTLER, 2010), isto é, são mais indignas que outras. Talvez se explique, a partir disso, o número alarmante de assassinatos de LGBTs com requintes de crueldade: expulsos de casa, do convívio familiar e social, sem ter quem chorar suas mortes, LGBTs são marcados 
como as vidas indignas, as vidas matáveis. Pululam relatos de travestis e transexuais, em situação de prostituição, que são abordadas, estupradas e presas com flagrantes forjados por policiais, simplesmente por ousarem desafiar o poder heterocisnormativo.

A sustentação do discurso heteronormativo, de economias de armário, apresenta como resultado imediato a invisibilidade de segmentos já opacos, como a população transexual e as travestis. Aliada à negação de direitos básicos, às interdições e à discriminação - vista principalmente na sacralização dos espaços públicos por meio do discurso de "lugar de respeito" - tem-se uma cidade interdita: uma cidade que nem todos podem acessar. Os mecanismos de controle dessa interdição são elementos sutis: através de micropoderes constituídos (como a religião e a família), interdita-se o sexo que contraria as normas sexuais tidas por legítimas, proíbe-se a sua expressão em público, reserva-se somente os espaços privados para o sexo possa falar de si, cria-se formas sutis de apagamento desses indivíduos marginais; afinal, se não se fala, não existe. Torna-se necessário e urgente romper com as portas dos armários societários, quebrando a economia sobre os corpos e desmantelando o regime de sexualidades lícitas/ilícitas, uma vez que representam uma opressão à população LGBT.

Muitas vezes o que se espera é que um artigo, após exaustivas páginas e análises, aponte o caminho a ser seguido, uma trilha mágica que resolverá todos os problemas apontados ao longo da teoria levantada. Este artigo não pretendeu ser um manual que porá fim à heterocisnormatividade da cidade. Faz-se primordial fortalecer uma cultura dos direitos humanos em que se tenha direito a ter direitos de cidadania e trazer à tona as discussões sobre a (re)apropriação dos espaços urbanos como espaços políticos. É necessário romper, na ótica da crítica ao/no Direito à Cidade, se romper com um modelo tão prejudicial e limitador de acesso à cidade e seus serviços: a heteronormatividade, apoiada pela reprodução do patriarcalismo e aprofundada pela luta de classes dentro da cidade. Propomos, deste modo, uma revolução urbana marginal, baseada na ressignificação e reconstrução do urbano a partir de uma compreensão emancipatória dos direitos, sobretudo, do direito à livre expressão de afetos na cidade. 


\section{Compreendemos, assim, que ou "expandiremos nuestras nociones de} los derechos para incluir a todo el mundo o trabajaremos para construir nociones de reconocimiento más robustas que nos permitan cierto tipo de relación recíproca y de armonía futura" (BUTLER, 2010, p. 224) ${ }^{8}$. 0 caminho ainda é incerto, as políticas do desejo também. Agora, mais do que nunca, as portas do armário na cidade se tornaram perigosas demais para não falarmos nelas.

\section{NOTAS}

1 "Quanto mais cresce a cidade, diz Lefebvre, quanto mais se desenvolve e se expande, estendendo seus tentáculos por todas as partes, mais se degradam as relações sociais, mais se desloca a sociabilidade em suas articulações". Tradução nossa.

2 A heterocisnormatividade refere-se à instituição da heterossexualidade (atração afetivo-sexual por indivíduo de gênero oposto) e da cisgeneridade (conformação da identidade de gênero com o sexo biológico designado ao nascer, a partir da genitália externa do indivíduo) enquanto naturais e, por conseguinte, legitimadas socialmente como o padrão a ser seguido, patologizando as demais orientações sexuais e identidades de gênero que fujam à norma.

3 Dados disponíveis em: <https://homofobiamata.files.wordpress.com/2017/12/relatorio-2081. pdf>. Acesso em: 18 jan. 2018.

4 Dados disponíveis em: <http://transrespect.org/en/tmm-update-trans-day-remembrance-2017/>. Acesso em: 18 jan. 2018.

5 "A imagem do assumir-se confronta regularmente a imagem do armário, e sua posição pública sem ambivalência pode ser contraposta como uma certeza epistemológica salvadora contra a privacidade equívoca oferecida pelo armário". Tradução nossa.

6 "[...] a prática subjetiva na qual se estabelecem as oposições de privado/público, dentro/fora, sujeito/objeto e se mantém inviolada a santidade do seu primeiro mandato. E o fenômeno do 'segredo aberto', como se poderia imaginar, não provoca o desmoronamento destes binarismos e seus efeitos ideológicos, mas sim constata seu reestabelecimento fantasmagórico". Tradução nossa. "Se certas vidas são consideradas merecedoras de viver, de proteção e de luto, e outras não, então esta maneira de diferenciar as vidas não pode ser entendida como um problema de identidade, tampouco do sujeito. A questão é mais como o poder forma o campo no qual os sujeitos se tornam possíveis ou como se tornam impossíveis. Isso implica em uma prática de pensamento crítico que se negue a dar por certo esse marco de luta identitária que pressupõe que esses assuntos já existem, que ocupam um espaço público comum e que suas diferenças poderiam se reconciliar dispondo, simplesmente, das ferramentas adequadas para os unir". Tradução nossa.

8 "Expandiremos nossas noções dos direitos para incluir todo mundo ou trabalharemos para construir noções de reconhecimento mais robustas que nos permitam certo tipo de relação recíproca e de harmonia futura". Tradução nossa. 


\section{REFERÊNCIAS}

BEAUVOIR, Simone de. El pensamiento político de la derecha. Tradução de Osiris Triani. Buenos Aires: Ediciones Siglo Veinte/ S.R.L. 1963.

BOURDIEU, Pierre. A dominação masculina. Rio de Janeiro: Bestbolso, 2014.

BUTLER, Judith. Marcos de guerra: las vidas lloradas. Ciudad de México: Paidós, 2010.

CARLOS, Ana Fani Alessandri. A (re)produção do espaço urbano. 1a ed. São Paulo: Editora da Universidade de São Paulo, 2008.

CARVALHO, Claudio; RODRIGUES, Raoni. 0 Direito à Cidade. Rio de Janeiro: Lumen Juris, 2016.

FOUCAULT, Michel. Microfísica do poder. Rio de Janeiro: Edições Graal, 1995.

FOUCAULT, Michel. História da Sexualidade I: a vontade de saber. $15^{a}$ ed. Rio de Janeiro: Edições Graal, 2003.

GRUPO GAY DA BAHIA. Relatório 2017: Mortes violentas de LGBT no Brasil. Disponível em: https://homofobiamata.files.wordpress.com/2017/12/ relatorio-2081.pdf . Acesso em: 18 jan. 2018.

HARVEY, David. Cidades rebeldes: do direito à cidade à revolução urbana. São Paulo: Martins Fontes - Selo Martins, 2014.

KELLER, Daniel Gevehr; ARAÚJO, Denise Castilhos; CORSO, Aline. “Ciberterritórios e masculinidades: o papel do discreto no aplicativo Scruff". In: Conexão comunicação e cultura, UCS, Caxias do Sul, v. 14, n. 27, jan./jul. 2015.

LEFEBVRE, Henry. 0 direito à cidade. São Paulo: Moraes, 1991.

LEMINSKI, Paulo. Toda poesia. 1ํㅡㄹ. edão Paulo: Companhia das Letras, 2013.

LEMOS, André. "Cibercultura e mobilidade: a era da conexão". In: XXVIII CONGRESSO BRASILEIRO DE CIÊNCIAS DA COMUNICAÇÃO, 2005. Rio de 
Janeiro. Disponível em: http://www.intercom.org.br/papers/nacionais/2005/ resumos/R1465-1.pdf. Acesso em: 18 nov. 2016.

LOPES, Débora. “'Não há nada de estranho comigo': a vida de uma travesti na terceira idade". In: Vice. São Paulo, 09 mar. 2016. Disponível em: http://www. vice.com/pt_br/read/travestis-envelhecimento. Acesso em: 20 nov. 2016.

MARX, Karl; ENGELS, Friedrich. A ideologia alemã. São Paulo: Expressão Popular, 2009.

MERRYFIELD, Andy. "El derecho a la ciudad y más allá: notas sobre una reconceptualización lefebvriana”. In: Urban, v. 1, n. 2, p. 101-110, set. 2011/ fev. 2012. 2011.

MILLETT, Kate. A Política Sexual. Lisboa: Publicações Dom Quixote, 1970.

MILLER, D. A. The novel and the police. 1988. In: SEDGWICK, Eve Kosofsky. Epistemología del armario. $1^{\mathfrak{a}}$ ed. Barcelona: Ediciones de la Tempestad, 1998.

MISKOLCI, Richard. “O armário ampliado - notas sobre sociabilidade homoerótica na era da internet". In: Gênero. Niterói, v. 9, n. 2, p. 171-190, 1º semestre de 2009.

MISSE, Richard. 0 Estigma do passivo sexual: um símbolo de estigma no discurso cotidiano. 3. ed. aumentada. Rio de Janeiro: NECVU/LeMetro, 2007.

ROLNIK, Raquel. Para além da lei: legislação urbanística e cidadania (São Paulo 1886-1936). 2009. Disponível em: https://raquelrolnik.files.wordpress. com/2009/08/paraalemdalei.pdf. Acesso em: 20 nov. 2016.

ROLNIK, Raquel. 0 que é cidade. $4^{\underline{a}}$ ed. São Paulo: Brasiliense, 2012.

WITTIG, Monique. The Straight Mind: and other essays. Boston: Beacon Press, 1992.

SANTOS, B. S.; AVRITZER, L. Para ampliar o cânone democrático. In: SANTOS, B. S. (Org.). Democratizar a democracia: os caminhos da democracia participativa. Rio de Janeiro: Civilização Brasileira, 2002. 
SANTOS, B. S. Democratizar a democracia: os caminhos da democracia participativa. Rio de Janeiro: Civilização Brasileira, 2002.

SANTOS, Milton. 0 espaço do cidadão. ${ }^{a}$ a ed. São Paulo: Editora da Universidade de São Paulo, 2014.

SEDGWICK, Eve Kosofsky. Epistemología del armario. 1a ed. Barcelona: Ediciones de la Tempestad, 1998.

SILVA, Joseli Maria. "A cidade dos corpos transgressores da heteronormatividade". In: Geo UERJ. Rio de Janeiro, ano 10, v. 1, n. 18, p. 3-19, 1º semestre de 2008.

SOUZA, M. L de. Mudar a cidade: uma introdução crítica ao planejamento e à gestão urbanos. Rio de Janeiro: Bertrand, 2003.

Enviado em: 26-6-2017

Recebido em: 22-7-2019

\section{Claudio Oliveira de Carvalho}

Doutor em Desenvolvimento Regional e Urbano; professor adjunto da Universidade Estadual do Sudoeste da Bahia (UESB). Membro do Instituto Brasileiro de Direito Urbanístico (IBDU); integrante do Núcleo de Assessoria Jurídica Alternativa (NAJA); e coordenador do Grupo de Pesquisa Direito e Sociedade (GPDS/CNPq). E-mail: ccarvalho@uesb.edu.br

\section{Gilson Santiago Macedo Júnior}

Graduando em Direito pela Universidade Estadual do Sudoeste da Bahia (UESB). Membro do Instituto Brasileiro de Direito Urbanístico (IBDU); integrante do Núcleo de Assessoria Jurídica Alternativa (NAJA); e integrante do Grupo de Pesquisa Direito e Sociedade (GPDS/CNPq).

E-mail: gilsonsantiago.06@gmail.com

Universidade Estadual do Sudoeste da Bahia

Estr. Bem Querer, Km-04 - 3293, 3391 - Campus de Vitória da Conquista - BA, 45083-900 